\title{
Attention to the production and construction of assembled concrete laminated plates
}

\author{
Xian Hong MENG ${ }^{1}$, Wei GUO ${ }^{1, a}$ \\ ${ }^{1}$ Department of Civil Engineering, Shenyang Jianzhu University, Shenyang, China
}

\begin{abstract}
. with the country of prefabricated construction vigorously promote, laminated concrete gradually into the line of sight of people, it not only has the factory production, convenient construction convenient, highlight the advantages of material saving, etc., this paper production and construction from the point of view of, the in the production process and Application of the discussion.
\end{abstract}

In the application of assembly construction, precast concrete composite plate has the advantages of saving formwork and supporting, quick and convenient construction, good economic benefits and so on. Due to its outstanding advantage countries began to vigorously promote the assembly of the type of construction, but because of our country in prefabricated construction area started late and some prefabricated components in production and construction exists many defects, this paper mainly from the perspective of the laminate floor of to explain it in the factory production process and problems that should be paid attention to in the construction site in the process.

\section{1 production matters needing attention}

In the production process should be considered during the construction of the floor and cast-in-place laminated layer as a whole, so in the production process of bottom surface should make bump not less than $4 \mathrm{~mm}$ artificial roughness surface so that the base plate can and superimposed layer better placement as a whole.

In order to meet the building warm water pipeline, laminated need opening in some of the construction process often by on-site construction workers digging, inevitably cut inside the soleplate by reinforcement, thereby reducing the slabs. Therefore laminate for opening to reserved hole (hole reinforced temporarily cut off) in factory production, stack layer of concrete pouring time to set aside the holes, laminated arrival intensity after resection of the hole steel.

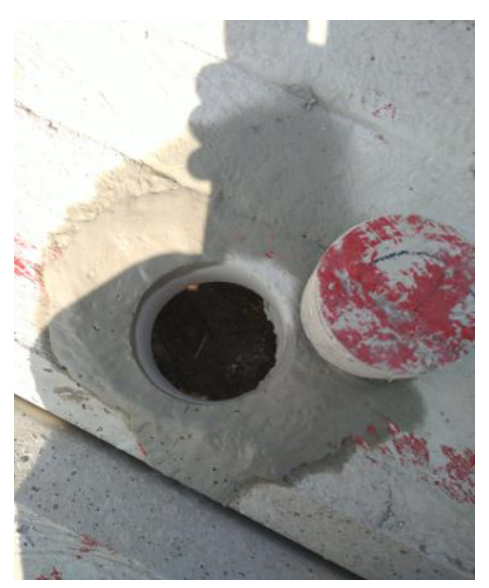

Floor openings

\section{Transportation and stacking problem of Composite Plates}

In order to prevent the laminate in transportation and stacking process failure, floor of the transportation, piling up process shall comply with the concrete structure engineering construction quality acceptance norms "GB50204-2002, the laminated prestressed concrete floor" GB/T16727-2007 provisions. In addition, the stack field shall be smooth and compact, stacking between the board and the ground should have a certain gap, and drainage facilities. Both ends of the board (board to end $200 \mathrm{~mm}$ ) and the cross position should be set when a pad pad wood, wood set cross sign in length $3.9 \mathrm{~m}$, two wooden cross flag set pad length $3.9 \mathrm{~m}$, pad wood should be on the alignment. Different plate number should be stacked, stacking height should not be more than 6 layers, stacking time should not exceed two months. Concrete strength to meet the design requirements of the rear to

\footnotetext{
${ }^{\mathrm{a}}$ Corresponding author: 1979173001@qq.com
} 
play and transport to firmly on a fulcrum lashing, beat to prevent movement or, in the concrete on the edge of the board or the rope at the point of contact should be protected by liner

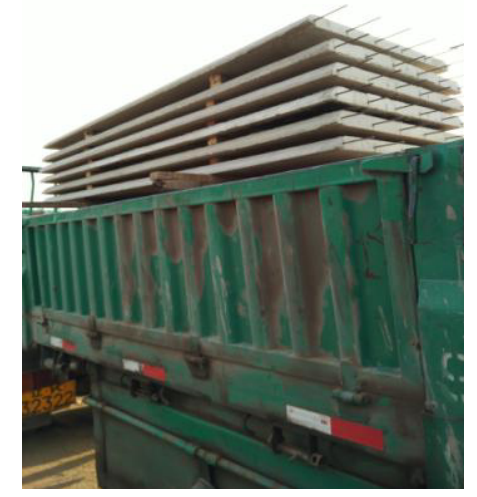

Floor transport

\section{3 hoisting problem}

Laminated hoisting process is the construction of a important link, in order to ensure the laminate can be safely lifting to a reasonable position, production manufacturers should design embedded rings position, to lifting does not occur when the eccentricity. The design height of rings, ensure the crane hook and the rings may not be stuck or crooked. In addition, taking into account the moment and deflection of the hoisting process of floor should be generated during lifting dynamic coefficient of 1.5. And the floor should be lifting floor number, so that the floor can be accurately placed in proper position, to prevent the two handling events, the maximum saving manpower. The temporary support should be installed in the front of the base plate in the middle of the span and close to the supporting seat. When the axial cross $3.9 \mathrm{~m}$ cross set in a support. When the axial cross $3.9 \mathrm{~m}$ cross set two support, support the top surface should be strictly copy flat, in order to ensure the flatness of the bottom plate, the support of all levels should be arranged in a vertical line.

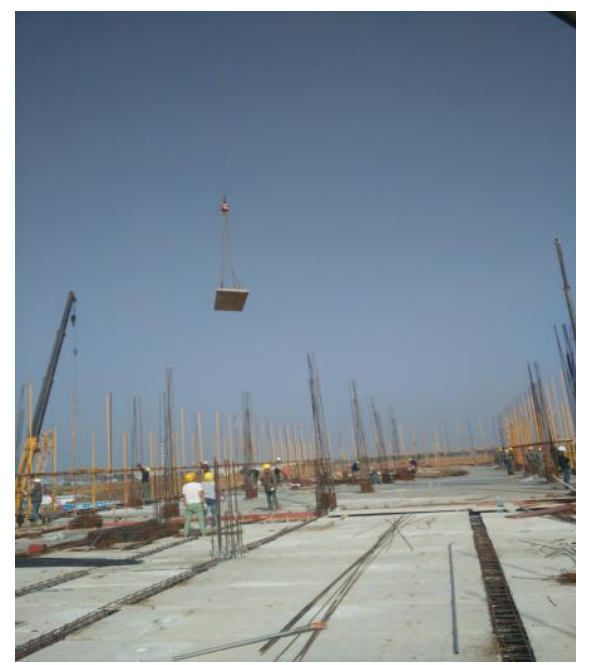

\section{4 splice structure of the composite plywood}

After floor hoisting in order to improve the laminated overall performance and shock resistance, formed in the bottom plate of rectangular holes interspersed with transverse reinforcement, the laminated stacked layers of cast-in-situ formed in two-way force, under normal circumstances plate and the plate gap mainly take two splicing way, a is in accordance with design drawings in the spaces placed transverse reinforcement, but this method at the construction site due to insecure reinforced easily lead to dislocation of reinforced, another it is directly on the floor laying the reinforcing mesh, the ways to save time and effort, and can improve floor carrying capacity.

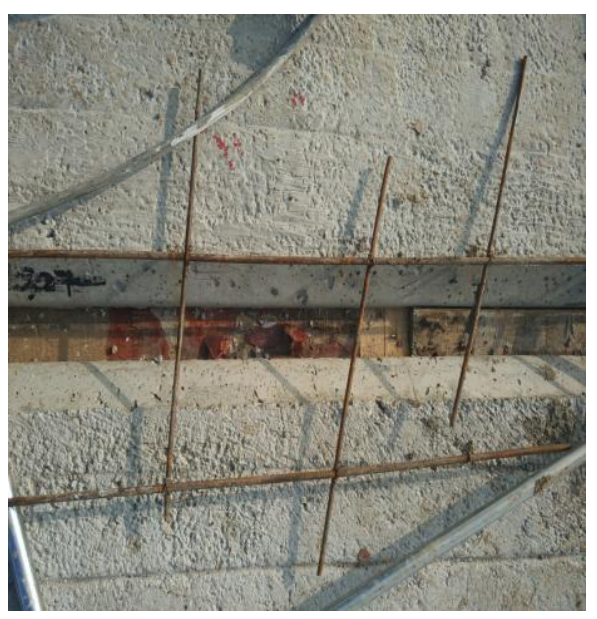

Seam reinforcement

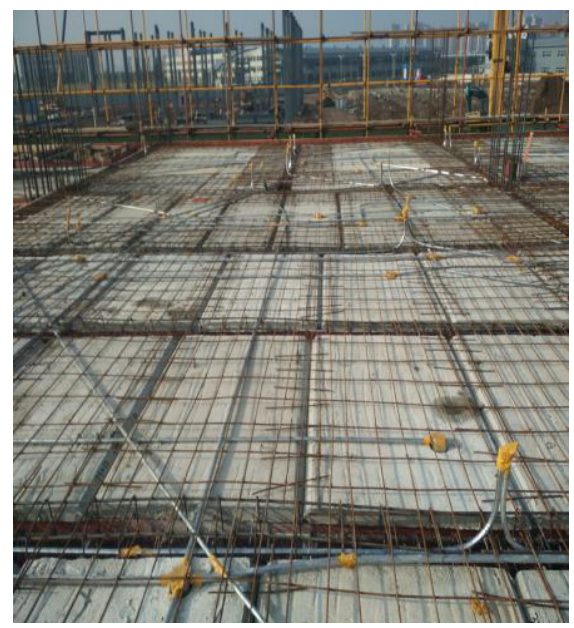

Steel mesh

In bottom plate and beam joint laminated prestressed 
tendon anchorage to the beam, need a crowbar to laminated prestressed reinforcement force anchorage to the beam within, resulting in deformation of beams with stirrups, and also brings difficulty to the construction itself, this time can be combined with the construction practice, through the opening of the hoop method to improve the construction.

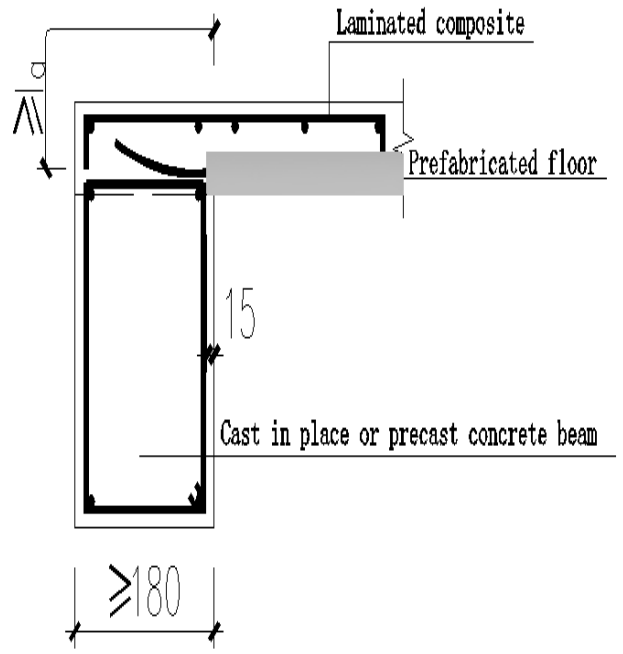

Plate beam Lap

\section{5 quality testing}

The quality acceptance of the components shall conform to the relevant provisions of the national standard "code for acceptance of construction quality of concrete structures" (2011 Edition), GB50204-2002 (EDITION).

The floor should be according to "laminated with bottom slab of prestressed concrete GB/T16727-2007" request the appearance inspection and testing.

The compressive strength of the concrete cube in the floor should be $100 \%$ after the design of concrete strength grade.

When testing the crack resistance of the base plate, we can take two points. When the other loading method is adopted, the value and the test index should be converted according to the principle of equivalent load effect.

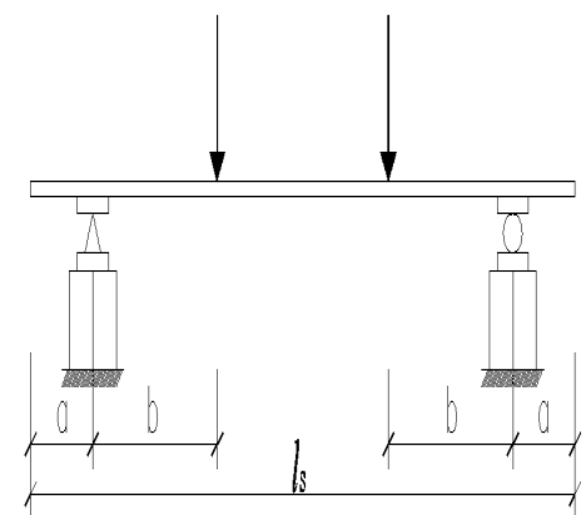

Loading sketch map

\section{6 conclusions and Outlook}

Precast ribbed composite not only has good integrity, two-way force, save supporting, highlight the advantages of convenient construction and obvious economic advantages, suitable for in housing construction vigorously promote the use of, the production and use of the prefabricated ribbed slabs should be the matters needing attention are reviewed, at present for ribbed precast laminated we still need to do the following research work.

To study the mechanical properties of prefabricated ribbed slab, to determine its mechanical properties, and give the calculation method, and finally form a complete design theory system.

To strengthen the construction of assembly type concrete construction work to ensure the smooth progress of the assembly and the quality of work.

\section{Acknowledgements}

This work is financially supported by Scientific research general project of Liao ning Provincial Department of Education(L2015310).

\section{References}

1. DBJT05-275 prestressed concrete laminated Atlas

2. GB50010-2010 design code for concrete structures

3. JCJ/T258-2011 Technical specification for prefabricated ribbed floor slab

4. Yao Yuan ,Zhang JingShu ,Liu Jun, Ni YongShong,Zhao Jun, Technical characteristics and economic comparison of precast slab with rib floor

5. Cui QingBiao , Prefabricated concrete structural member and construction matters needing attention

6. Pan Yanhua Study on mechanical behavior of PK prestressed concrete composite slab 